\title{
Spatial and temporal variations of chlorophyll-a concentration from 2009 to 2012 in Poyang Lake, China
}

\author{
Juanle Wang $\cdot$ Yongjie Zhang $\cdot$ Fei Yang $\cdot$ \\ Xiaoming Cao $\cdot$ Zhongqiang Bai $\cdot$ Junxiang Zhu $\cdot$ \\ Eryang Chen $\cdot$ Yifan Li $\cdot$ Yingying Ran
}

Received: 21 March 2014/ Accepted: 5 September 2014/Published online: 26 September 2014

(c) Springer-Verlag Berlin Heidelberg 2014

\begin{abstract}
Water eutrophication in Poyang Lake, the largest freshwater lake in China, has been considered to be an obstacle to aquatic environment protection and regional sustainable development. Chlorophyll- $a$ concentration is one of the most important indices of water eutrophication. This paper builds seasonal chlorophyll- $a$ concentration retrieval models using a semi-analytical model. Quarterly distributions of chlorophyll- $a$ concentration from 2009 to 2012 are explored using multi-spectra data from a moderate-resolution imaging spectroradiometer (MODIS). The correlation coefficient of the retrieval models primarily ranged from 0.6 to 0.9 . The results show that the chlorophyll- $a$ concentration in Poyang Lake has significant seasonality characteristics that present low values in the winter and spring, and present relatively high values in the summer and autumn; this report also presents an obvious, increasing trend of inter-annual variability from 2009 to 2012. The spatial distribution of the chlorophyll- $a$ concentration has regional differences that give relatively high values adjacent to the shore in the north area of Poyang Lake, in the flow in river entries, and in the main channel
\end{abstract}

J. Wang $(\bowtie) \cdot$ Y. Zhang · F. Yang · Z. Bai · J. Zhu · E. Chen ·

Y. Li

State Key Laboratory of Resources and Environmental Information System, Institute of Geographic Sciences and

Natural Resources Research, Chinese Academy of Sciences,

Beijing 100101, China

e-mail: wangjl@igsnrr.ac.cn

\section{Cao}

Institute of Desertification Studies, Chinese Academy of Forestry, Beijing 100091, China

Y. Ran

Tianjin Land Resources and House Vocational College,

Tianjin 300270, China area in the central and south areas of Poyang Lake. The natural hydrology features have a close relationship with the variation in the chlorophyll- $a$ concentration. Intensive human activities are the main driving forces for the increasing chlorophyll- $a$ concentration.

Keywords Water color remote sensing - Retrieval model - Chlorophyll- $a$ concentration - Spectral analysis . Remote-sensing inversion · Poyang Lake

\section{Introduction}

Eutrophication is the primary water-quality issue affecting freshwater and coastal marine ecosystems throughout the world (Smith and Schindler 2009). Chlorophyll- $a$ concentration is an important index characterizing the physicochemical properties of the dynamically changing lake water, and it has been a very important lake eutrophicationmonitoring indicator. Many lakes in China are threatened by eutrophication, in particular those located along the middle and lower reaches of the Yangtze River (Huang et al. 1998; Jin et al. 1999; Zhao et al. 2002; Yan et al. 2003). Poyang Lake is the largest freshwater lake in China, and it plays an important role in biodiversity conservation, water-resource management and flood control. In recent years, rapid economic growth and an increase in the resource exploitation intensity in the Poyang Lake basin area have caused the outflow of nitrogen and phosphorus into lakes. This, in turn, has led to the water-quality deteriorating, a high risk of more severe lake eutrophication (Wang 2008), more frequent outbreaks of algal blooms, and the degradation of lake ecosystems (Deng et al. 2011).

Therefore, it is important to monitor water quality effectively and to understand how the health of Poyang 
Lake is affected by multifarious natural and anthropogenic factors. The traditional method of field monitoring at several discrete stations at regular intervals is not only moneyand time-consuming; but also is inadequate to observe temporal and spatial variations over a large area (Yu et al. 2012). Remote sensing can effectively facilitate the collection of water-quality data over a large area simultaneously (Dekker et al. 2001, 2002). The moderateresolution imaging spectroradiometer (MODIS) is a key instrument aboard the Terra and Aqua satellites launched by the National Aeronautics and Space Administration (NASA) in 1999 and 2001, respectively (http://modis.gsfc. nasa.gov). With advantages such as medium spatial resolution, daily coverage, high sensitivity, and cost-free distribution ( $\mathrm{Li}$ and $\mathrm{Li}$ 2004; Miller and McKee 2004), MODIS sensors have collected massive quantities of Earthsurface data for more than 10 years and provide great opportunities for monitoring and analyzing the long-term spatiotemporal dynamics of chlorophyll- $a$.

Three types of models have generally been used to retrieve chlorophyll- $a$ concentration values: empirical, semi-analytical and analytical (Chen et al. 2013a). The 'empirical model' was established using the relationship between water's optical properties and components (Chen et al. 2011; Matthews 2011). This model is simple and easily implemented. However, it cannot be applied in other areas when optical properties are different from those used for model development. The analytical models relied on serious theory, but their applications are limited because of difficulties or inaccuracies in obtaining model-driving parameters (Sipelgas et al. 2009; Binding et al. 2010, 2012). The semi-analytical model is based on the relationship between the inherent optical properties of water and chlorophyll- $a$ concentration, plus some empirical relationships (Chen et al. 2013b; Gitelson et al. 2008; Carder et al. 2004). This model combines a remote-sensing reflectance theoretical model with optical properties by taking advantage of known optical properties of specific substances. As chlorophyll- $a$ concentration measured data are obtained more conveniently, there have been an increasing number of applications based on the semi-analytical model (Wu et al. 2013b).

Gitelson et al. (2008) used the three-band model in chlorophyll- $a$ concentration retrieving. Chen et al. (2013c) improved the three-band model and discussed four-band model applicability in chlorophyll- $a$ concentration retrieving in Taihu Lake and the Yellow River estuary. Jiang (2012) estimated the chlorophyll- $a$ concentration distribution of Poyang Lake in 2011 using a field-spectrum survey and retrieval-model construction with MODIS data; however, the accuracy of the retrieval model was low. Huang et al. (2010) established the chlorophyll- $a$ concentration retrieval model of Poyang Lake in 2010 based on a regression and the BP neural network method. Wang et al. (2007) evaluated the eutrophication level with a hyperspectrum retrieval model through analysis of a field survey of the water spectrum and water parameters.

Although there were a few chlorophyll- $a$ concentration monitoring studies in Poyang Lake, most of them could not provide a baseline of the temporal and spatial distribution of chlorophyll- $a$ concentration for the long term. There could be two reasons for this: (1) Because Poyang Lake had a relatively low eutrophication level for China, it was difficult to measure chlorophyll- $a$ concentration by remote sensing. (2) Poyang Lake's water surface has typically seasonality features because it is a passing water lake. Only monitoring the seasonal change features of chlorophyll$a$ concentration would have significance for Poyang Lake water environmental management. This needs long term, at least seasonal scale, field station monitoring support. However, the field station for special water environmental and ecosystem management was very limited before 2009 . This caused a lack of long-term chlorophyll- $a$ concentration monitoring in this lake.

The primary objective of this study is to estimate and illustrate the temporal and spatial distribution characteristics of the chlorophyll- $a$ concentration in Poyang Lake by employing field station seasonal monitoring data from 2009 to 2012. The manuscript is arranged as follows: Poyang Lake and its environmental setting are first introduced, followed by a methodology to use MODIS data for the construction of chlorophyll- $a$ concentration retrieving models and for field data collection. Then, retrieval-model construction is performed and applied to the chlorophyll$a$ concentration temporal and spatial distribution from 2009 to 2012. Finally, quarterly spatial and temporal patterns of the chlorophyll- $a$ concentration distribution of Poyang Lake, as well as its inter-annual and inner-annual variation, are presented and discussed.

\section{Materials and methods}

\section{Study area}

Poyang Lake $\left(28^{\circ} 22^{\prime}-29^{\circ} 45^{\prime} \mathrm{N}, 115^{\circ} 47^{\prime}-116^{\circ} 45^{\prime} \mathrm{E}\right)$ is located in the north of Jiangxi province at the south bank of the middle and lower reaches of the Yangtze River. Poyang Lake has a drainage basin area of 162,225 km², accounting for $\sim 97 \%$ of the area of Jiangxi province (Shankman and Liang 2003). Poyang Lake receives water mainly from five inflowing rivers, namely the Xiushui River, the Ganjiang River, the Fu River, the Xinjiang River and the Rao River, and it drains into the Yangtze River through a narrow channel at Hukou in the north (Fig. 1). 


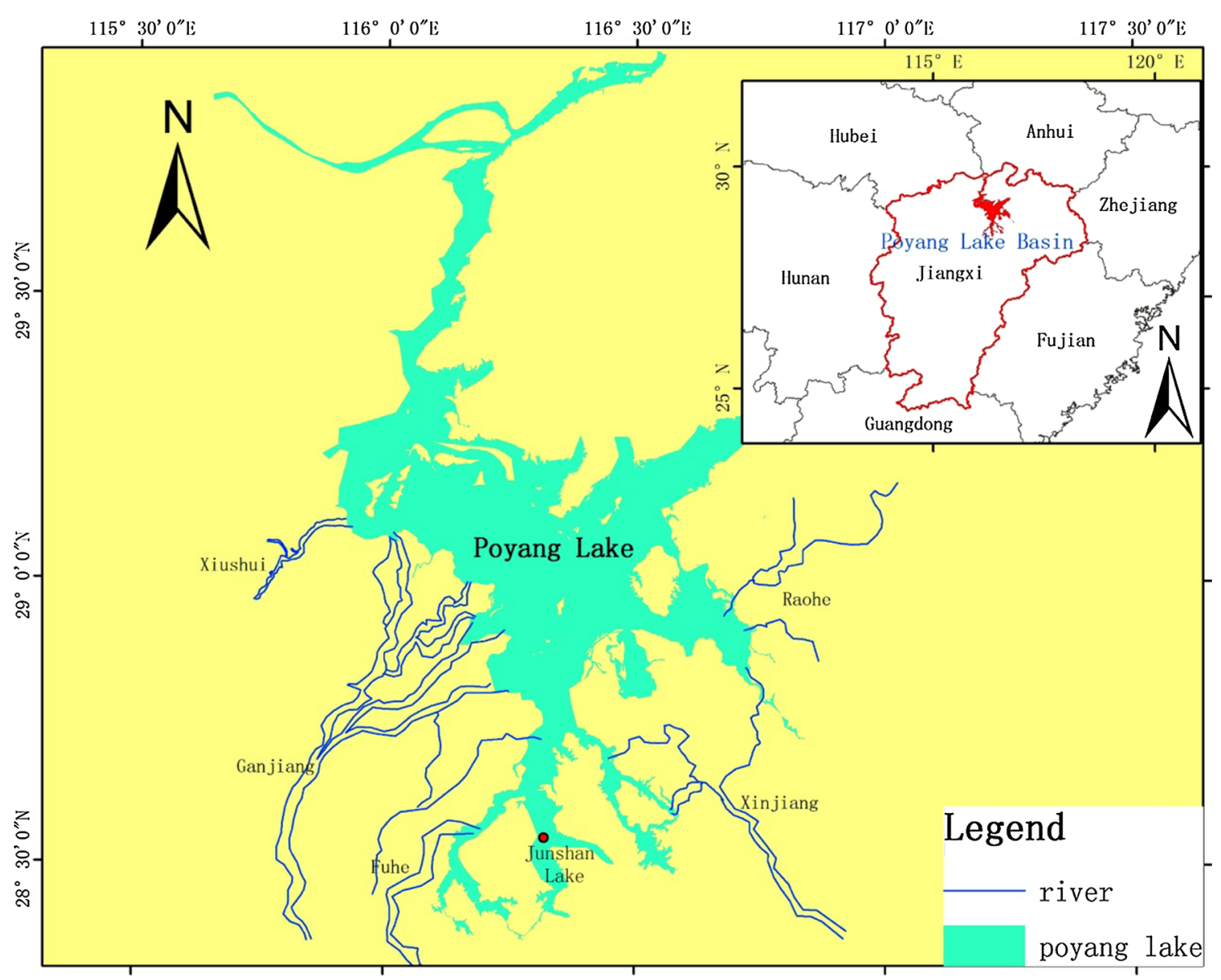

Fig. 1 Location of Poyang Lake

The Poyang Lake region is influenced by subtropical monsoons (Zhang 1988) and the seasonality of precipitation combined with smooth relief factors. This results in significant fluctuations of the inundation area of the lake throughout the year. During the wet season from April to September, the floodplains are inundated and form a large lake with an inundation area reaching $>4,000 \mathrm{~km}^{2}$ (Xu et al. 2001; Shankman et al. 2006). The often-elevated water level of the Yangtze River (sometimes even with reverse flow) between July and September also increases the inundation area of the lake. During the dry season from October to March, the inundation area of the lake can shrink to $<1,000 \mathrm{~km}^{2}$ to form a narrow, meandering channel.

In addition to the flood-adjustment function, Poyang Lake also plays significant, local social and economic sustainable development roles, as well as a role in global ecological conservation. The lake is an internationally important wetland with a rich biodiversity of 102 species of aquatic plants and 122 species of fish. It also is one of the largest bird-conservation areas in the world, hosting millions of birds of over 300 species (Wu and Ji 2002).
Fieldwork

\section{Chlorophyll-a measurement}

To monitor the baseline-environment conditions in the Lake, Poyang Lake Laboratory for Wetland Ecosystem Research (PLWER) was built in 2008. It belonged to the Nanjing Institute of Geography \& Limnology, Chinese Academy of Sciences. Since January 2009, regular observation of water-quality parameters has been conducted each season (Wu et al. 2013b). The sampling dates are in the middle of January, April, July, and October, and last for 5-10 days each time.

Vertically integrated water samples were obtained and placed into acid-cleaned 10-L plastic containers and kept cool and shaded before being transported to the laboratory. Environmental parameters including $\mathrm{pH}$, water temperature, dissolved oxygen, turbidity, and electrical conductivity, were measured using a Hydrolab Datasonde 5 sensor in situ (Wu et al. 2013b).

The chlorophyll- $a$ concentration was collected on-site and analyzed in PLWER. A spectrophotometry method 
(a)

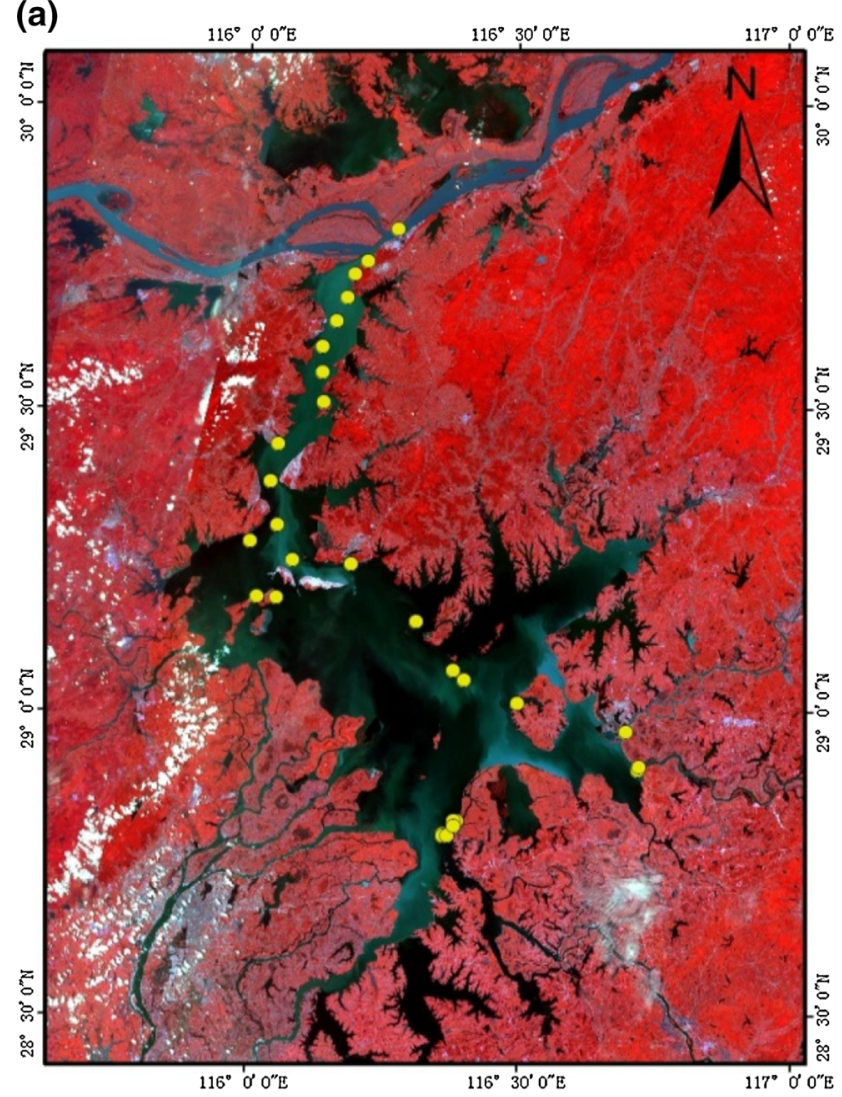

(b)

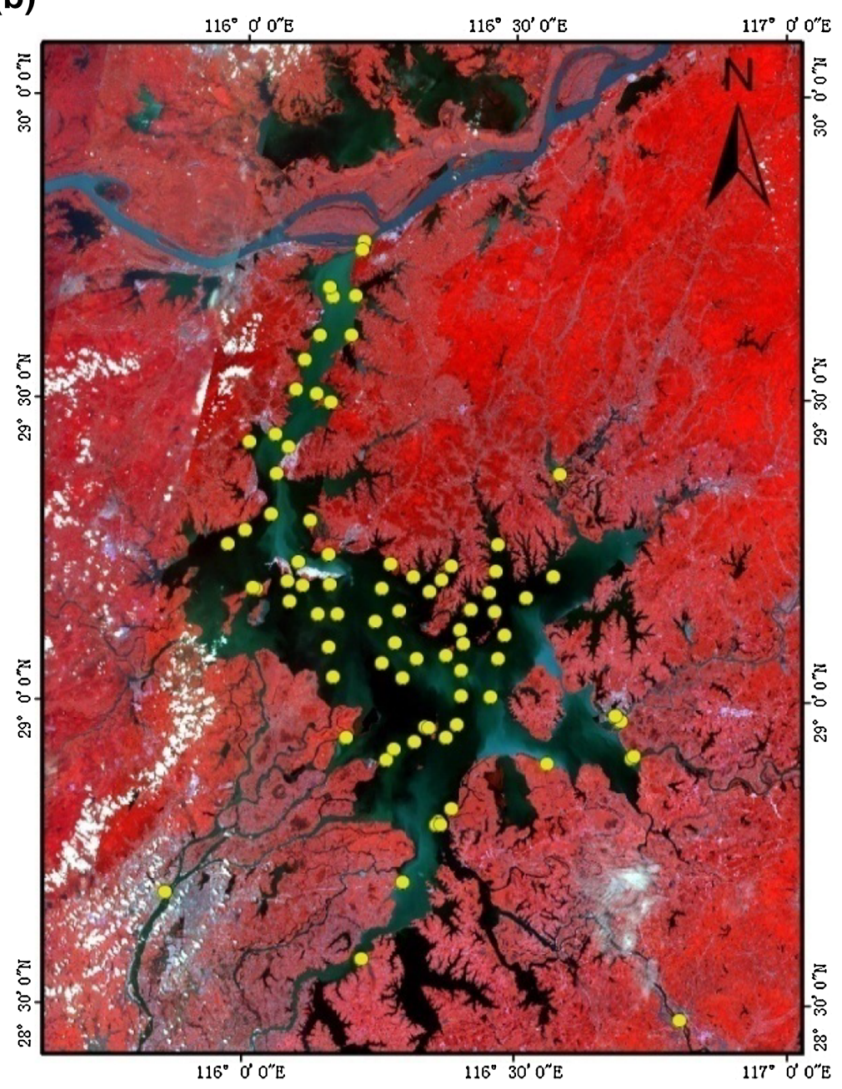

Fig. 2 Sampling-point distribution in Poyang Lake in the dry season (a) and the wet season (b)

was applied for laboratory analysis (Unesco 1966). The processes for the laboratory determination were: (1) sample filtration, (2) membrane freezing, (3) dissolution of chlorophyll, (4) a second sample filtration, (5) colorimetric analysis (754 UV-Vis spectrophotometry), and (6) calculation of the chlorophyll- $a$ concentration.

\section{Spectral measurement}

Hyperspectral data of the water surface were measured simultaneously with the in situ measurement of waterquality parameters on October 15-19, 2011, July 6-12, 2012 and October 12-15, 2012. The sampling points are shown in Fig. 2. Figure 2a shows that water-quality parameters and water reflectance were synchronously measured at 24 sampling points in the dry season. Due to the expanded water surface in the wet season, more sampling points (78 points total) were measured in July 2012, as shown in Fig. 2b.

Based on the apparent optical parameters method (Tang 2004), the above water spectral remote-sensing reflectance $\left(R_{\mathrm{rS}}\right)$ of every point was measured using an ASD FieldSpec $\mathrm{HH}$ field portable spectroradiometer with a 1-nm sampling interval and 325-1,075 $\mathrm{nm}$ of spectral resolution. The measurement parameters included $L_{\mathrm{sw}}$ (the measured value of the instrument to the water surface), $L_{\text {sky }}$ (the measured value of the instrument to the sky light), $L_{\mathrm{p}}$ (the measured value of the instrument to the reference plate), and $L_{\mathrm{pdif}}$ (the measured value of the instrument to the reference plate against sunlight). Remote-sensing reflectance $R_{\mathrm{rs}}$ was calculated using the following equation:

$R_{\mathrm{rs}}=\frac{L_{\mathrm{w}}}{E_{\mathrm{d}}\left(0^{+}\right)}=\frac{L_{\mathrm{sw}}-r L_{\mathrm{sky}}}{\pi \cdot L_{\mathrm{p}}} \cdot \rho_{\mathrm{p}}$

where $R_{\mathrm{rs}}$ is remote-sensing reflectance; $L_{\mathrm{w}}$ is water radial brightness; $r$ is the reflectance of the atmosphere-water boundary in the face of the sky light; $E_{\mathrm{d}}\left(0^{+}\right)$is the water surface incident irradiance; $L_{\mathrm{p}}$ is the measured value of the standard gray board; and $\rho_{\mathrm{p}}$ is the reflectance of the standard gray board.

\section{Methods}

Image acquisition and pre-processing

MOD09 data sets, the second-level standard products of MODIS, were selected for the chlorophyll- $a$ concentration estimation. They were processed by the four following steps. (1) Reprojection processing: the MODIS Reprojection Tool (MRT) was used to transfer the image projection 
from the original sinusoidal projection to the Albers Conical Equal Area project. (2) Cutting processing: the Poyang Lake area in the images was drawn artificially in the rectangular area. (3) Surface reflectivity transformation: the surface reflectivity was converted to between 0 and 1. (4) Resample processing: band 3 and band 5 of the MODIS image were resampled to $250-\mathrm{m}$ resolution from $500-\mathrm{m}$ resolution.

\section{Water surface area extraction}

There are several water surface area extraction methods, such as the Normalized Difference Vegetation Index (NDVI) (Domenikiotis et al. 2003; Lunetta et al. 2006), the Normalized Difference Water Index (NDWI) (Jain et al. 2005; Xu 2006), the spectrum-photometric method (Zhou et al. 2003), etc. The Floating Algae Index (FAI) method was a new method introduced in 2009 (Hu 2009). It was

Table 1 Hyperspectral spectral indices for estimating the chlorophyll- $a$ concentration

\begin{tabular}{ll}
\hline Spectral indices & Calculation formula \\
\hline Difference $(D)$ & $R_{\lambda_{1}}-R_{\lambda_{2}}$ \\
Simple ratio (SR) & $R_{\lambda_{1}} / R_{\lambda_{2}}$ \\
$R_{\lambda_{1}}$ normalized difference (ND) & $\left(R_{\lambda_{1}}-R_{\lambda_{2}}\right) /\left(R_{\lambda 1}+R_{\lambda 2}\right)$ \\
Reflectance $(R)$ & $R_{\lambda_{1}}$ \\
\hline
\end{tabular}

used successfully in the water surface extraction of Poyang Lake. Its calculation algorithm is shown in formula 2: $\mathrm{FAI}=R_{\mathrm{rc} 859}-R_{\mathrm{rc} 859}^{\prime}$

$$
\begin{aligned}
R_{\mathrm{rc} 859}^{\prime}= & R_{\mathrm{rc} 645}+\left(R_{\mathrm{rc} 1240}-R_{\mathrm{rc} 645}\right) \times(859-645) \\
& /(1240-645)
\end{aligned}
$$

where $R_{\mathrm{rc} 645}, R_{\mathrm{rc} 859}$, and $R_{\mathrm{rc} 1240}$ are the remote-sensing reflectance of the red, near-infrared and short-wave infrared wavelengths in the MODIS images, respectively. $R_{\mathrm{rc} 859}^{\prime}$ means theoretical reflectance.

The FAI method can eliminate the influence of environmental variables using an effective combination of red, near-infrared and short-wave infrared wavelengths. Due to the strong absorption and weak backscattering effect of water in the near-infrared band, the FAI value of the water is much lower than that of the land.

\section{Chlorophyll-a concentration retrieval method}

A semi-analytical method was used to construct the retrieval models of the chlorophyll- $a$ concentration of Poyang Lake from 2009 to 2012. A sensitive wavelength interval was initially discovered; then, the chlorophyll$a$ concentration retrieval models of three spectrum-measured seasons were constructed. Based on the retrieval models and the chlorophyll- $a$ concentration values measured in situ, other seasons' optimal retrieval models
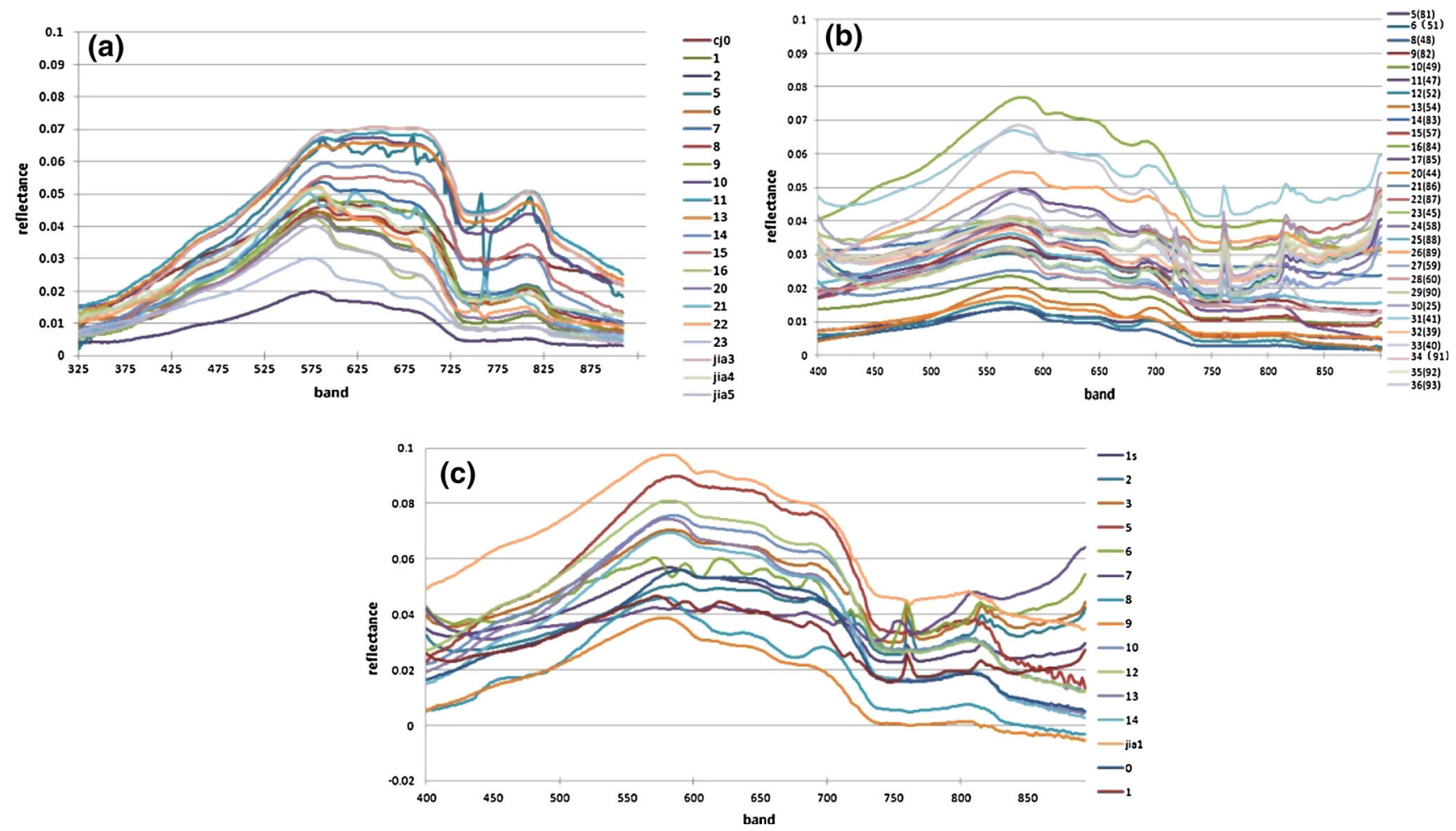

Fig. 3 Spectral reflectance of Poyang Lake for: a October 2011; b July 2011; and c October 2012 
without spectrum measured from 2009 to 2012 were constructed. Finally, the accuracy of all the seasons' retrieval models was evaluated.

Spectral indices were used to select the sensitive spectral bands for chlorophyll- $a$ concentration retrieval because they could maximize the spectrum sensitivity characteristics and minimize the influence of other factors $(\mathrm{Wu}$ and Wang 2005; Liu et al. 2012). To find the sensitive band for chlorophyll- $a$ concentration estimation, four types of spectral indices were constructed: the difference index $(D)$, the simple ratio index (SR), the normalized difference index (ND) and the single-band index $(R)$. These spectralindex calculation formulas are shown in Table $1\left(R_{\lambda 1}\right.$ and $R_{\lambda 2}$ represent the spectral reflectance of wavelengths $\lambda_{1}$ and $\lambda_{2} \mathrm{~nm}$ ). The conventional least squares method was used to calculate the correlation coefficient $\left(R^{2}\right)$, the root mean square error (RMSE) and the average relative error (PRMSE) by iterative regression analysis between the spectral indices and the measured water chlorophyll$a$ concentration in situ. The optimal spectral index can be selected with $\max R^{2}$.

\section{Chlorophyll-a concentration retrieval accuracy evaluation}

The chlorophyll- $a$ retrieval-model accuracy was verified using verification points that were not used for the model construction. The verification algorithm is described by formula 3:

Relative error $(\%)$
$=\frac{\text { the inversion values }- \text { the measured values }}{\text { the measured values }} \times 100 \%$

\section{Chlorophyll-a concentration fluctuation degree calculation}

Because of the seasonal variation of the water surface boundary of Poyang Lake, a standard deviation method was used to compare the fluctuation degree of the chlorophyll- $a$ concentration in the same season of different years from 2009 to 2012 . The standard deviation formula is shown in formula 4 :

$\sigma=\sqrt{\frac{1}{N-1} \sum_{i=1}^{N}\left(x_{i}-\mu\right)^{2}}, \mu=\frac{1}{N} \sum_{i=1}^{N} x_{i}$

where $\sigma$ represents the standard deviation of the chlorophyll- $a$ concentration, $N$ is the number of years, $x_{i}$ is the chlorophyll- $a$ concentration for each year, and $\mu$ is the average value of the chlorophyll- $a$ concentration for all of the years.

\section{Results}

Chlorophyll- $a$ concentration retrieval-model construction

\section{Retrieval-model construction in seasons with spectrum} measurement

The water spectra measured in October 2011, July 2012 and October 2012 were processed by abnormal spectrum elimination, normalized processing and first-order derivative treatment, as shown in Fig. 3, respectively.

Three sensitive wavelength intervals were discovered. The most sensitive bands were $680-710$ vs. $654-700 \mathrm{~nm}$

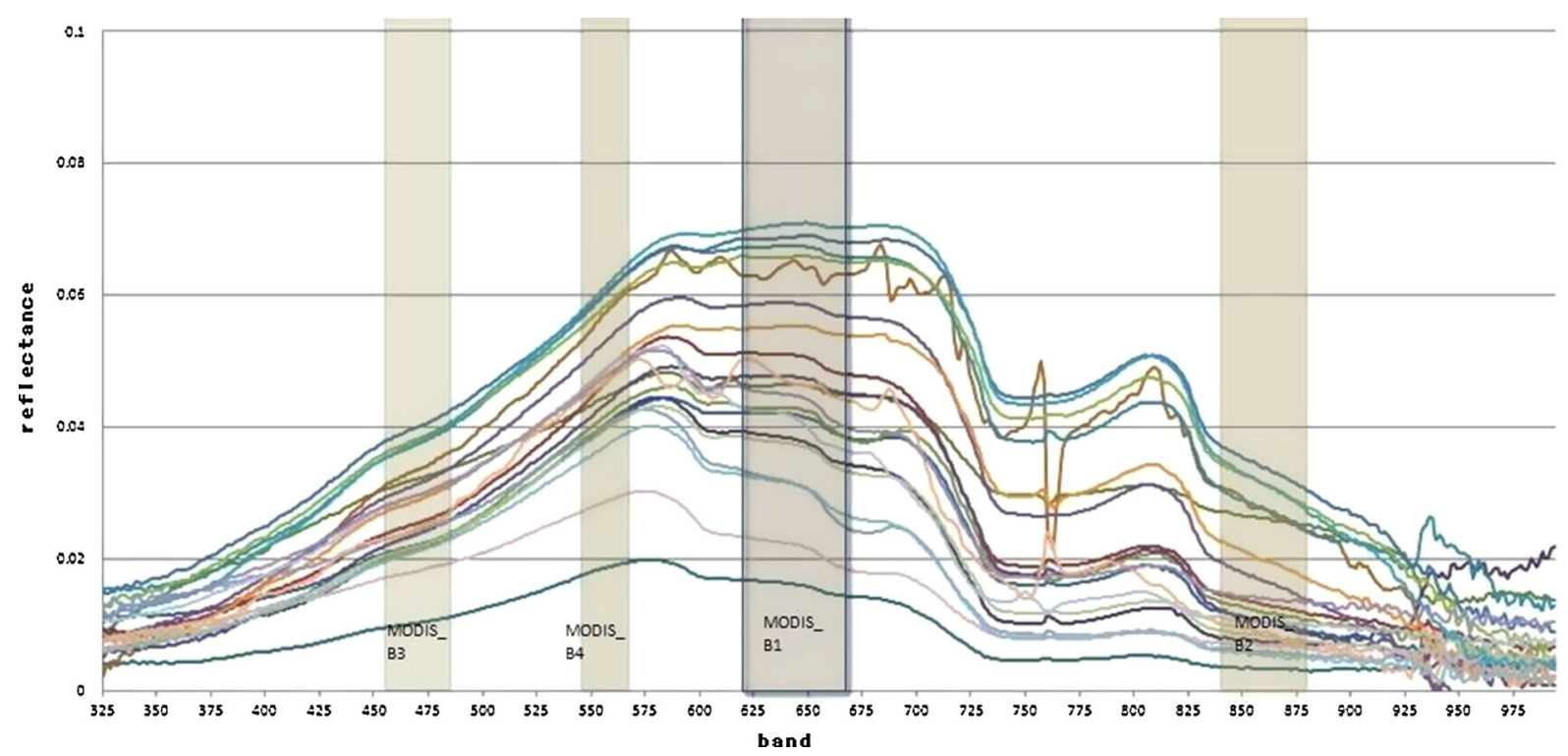

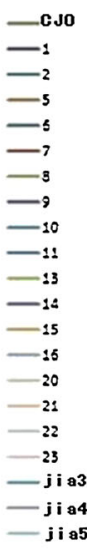

Fig. 4 The scope of the MOD09 band corresponding to the measured spectrum in Poyang Lake 
combination in October 2011; the 660-700 vs. 682-720 nm combination in July 2012; and the 590-700 vs. $540-620 \mathrm{~nm}$ combination in October 2012. Figure 4 shows that MODIS data-channel 1, 3, and 4 bands closely correlated with the chlorophyll- $a$ concentration. Previous studies showed that a large quantity of spectral information for the chlorophyll- $a$ concentration shifted to longer wavelengths (near-infrared band). This was caused by the high suspended concentration of water in Poyang Lake (Härmä et al. 2001; Liu et al. 2009; Zhang et al. 2013). MODIS band 2 covered the 841-876 nm near-infrared wavelength band range and was chosen as optimal for chlorophyll- $a$ concentration extraction.

Through the comparison of different spectrum indices as shown in Table 1, three spectral measured seasons' chlorophyll- $a$ concentration retrieval models were discovered. Figure 5 shows that the chlorophyll- $a$ concentration and the spectral relationship could be simulated well by the formula $Y=e^{a x+b}$.

\section{Retrieval-model construction in the seasons without spectrum measurement}

The retrieval models of chlorophyll- $a$ concentration in the seasons without spectrum measurement were constructed based on a semi-analytical model built above and a regression analysis between measured chlorophyll- $a$ concentration sample values and the quasi-synchronous MODIS data. A quarterly optimal chlorophyll-a retrieval model was discovered with a maximized correlation coefficient and a minimized RMSE.

These retrieval models are listed in Table 2. The results for the simulation were evaluated by RMSE and F statistics. The results show that the chlorophyll- $a$ concentration retrieval models had a high reliability overall from 2009 to 2012. Most of the models had a steady and relatively high $R^{2}(>0.6)$ value, although there were several low values in the winter and spring dry season.

\section{Retrieval-model verification}

The quarterly average relative error from 2009 to 2012 is listed in Table 3. It shows that accuracy of the retrieval models of the chlorophyll- $a$ concentration ranged from 60 to $90 \%$, average relative errors ranged from 16.5 to $52.5 \%$, and the mean value is $35.8 \%$. Two high average relative errors existed in January and April 2009. The low accuracy in several seasons may be explained by the following. First, the chlorophyll- $a$ spectral information is very weak in a high suspended material concentration environment ( $\mathrm{Yu}$ et al. 2012). Second, the range of the Poyang Lake water surface changed greatly on a seasonal basis. Many sampling points could not be measured in the dry seasons (January and April) because they were exposed on the lake bottom, thus leading to a decrease in the number of sampling points. Third, the overall values of the chlorophyll- $a$ concentrations of Poyang Lake were low; its spatial heterogeneity was obvious (there existed significantly higher values in certain areas), which could easily lead to errors increasing. Finally, the initial sampling points were not sufficient in 2009 when PLWER started working. Against this background, retrieval-model accuracy was positive and could be accepted for chlorophyll- $a$ concentration estimation in a long seasonal series.

Spatial and temporal distribution of chlorophyll- $a$ concentration

Chlorophyll- $a$ concentration distributions for each season in Poyang Lake from 2009 to 2012 are shown in Fig. 6. It shows obvious seasonal distribution characteristics. In
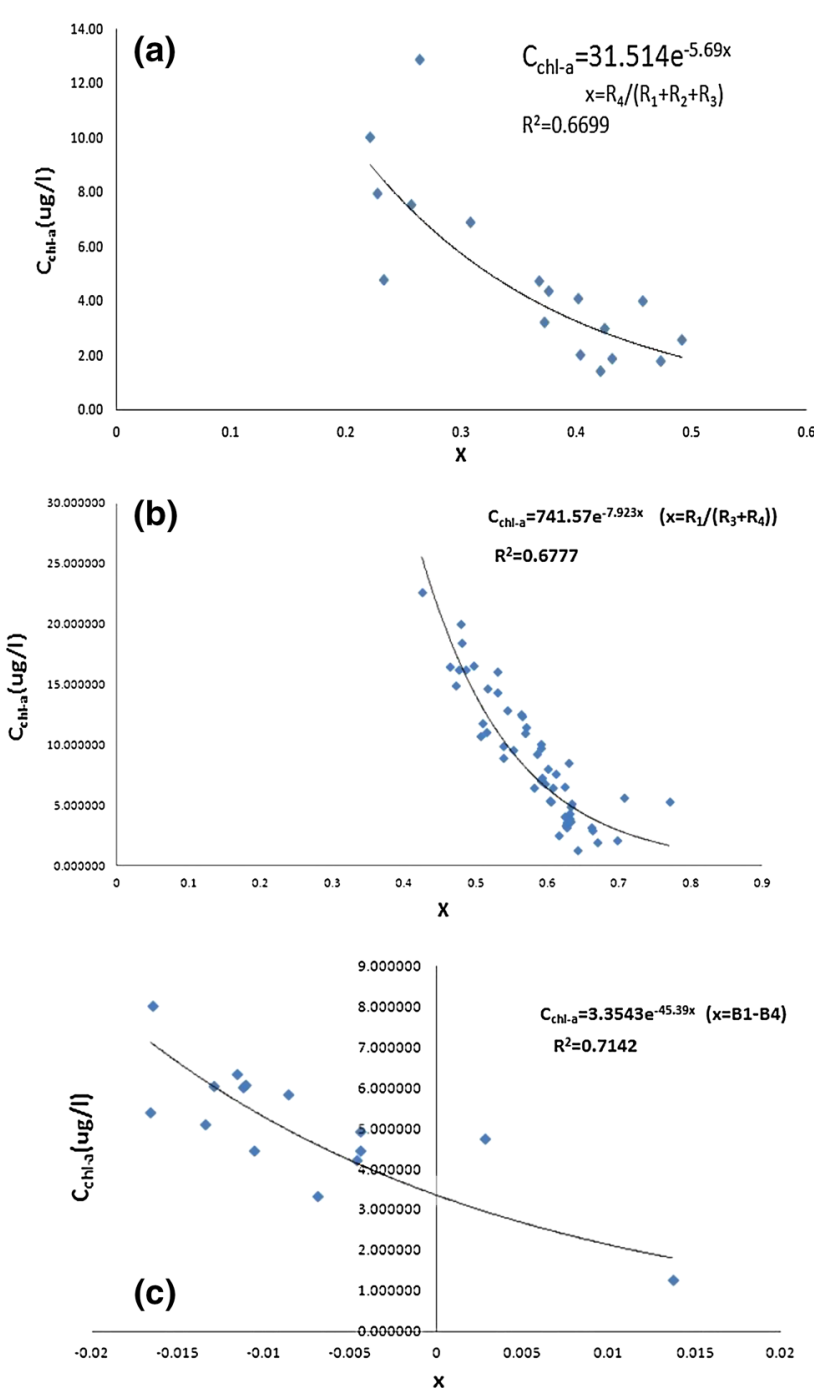

Fig. 5 Chlorophyll- $a$ concentration retrieval models in October 2011 (a), July 2012 (b), October 2012 (c) 
Table 2 Seasonal regression models of the chlorophyll- $a$ concentration in Poyang Lake from 2009 to 2012

\begin{tabular}{|c|c|c|c|c|c|c|}
\hline Index of the model & The inversion model & Month & $R^{2}$ & RMSE & $F$ & $P$ \\
\hline$X=\mathrm{B} 1 /(\mathrm{B} 2+\mathrm{B} 3+\mathrm{B} 4)$ & $Y=0.7969 \times \operatorname{EXP}(-2.6605 X)$ & January 2012 & 0.453 & 0.27 & 7.44 & 0.0232 \\
\hline$X=\mathrm{B} 1 /(\mathrm{B} 2+\mathrm{B} 3+\mathrm{B} 4)$ & $Y=19.148 \times \operatorname{EXP}(-3.235 X)$ & April 2012 & 0.513 & 2.11 & 13.68 & 0.0027 \\
\hline$X=\mathrm{B} 1 /(\mathrm{B} 3+\mathrm{B} 4)$ & $Y=741.57 \times \operatorname{EXP}(-7.923 X)$ & July 2012 & 0.678 & 2.22 & 107.23 & $3.8 \mathrm{E}-14$ \\
\hline$X=\mathrm{B} 1-\mathrm{B} 4$ & $Y=3.354 \times \operatorname{EXP}(-45.39 X)$ & October 2012 & 0.714 & 0.95 & 32.49 & $7.3 \mathrm{E}-05$ \\
\hline$X=\mathrm{B} 1 /(\mathrm{B} 2+\mathrm{B} 3+\mathrm{B} 4)$ & $Y=66.414 \times \operatorname{EXP}(-4.925 X)$ & January 2011 & 0.678 & 1.64 & 14.71 & 0.0064 \\
\hline$X=\mathrm{B} 1 /(\mathrm{B} 2+\mathrm{B} 3+\mathrm{B} 4)$ & $\mathrm{Y}=24.77 \times \operatorname{EXP}(-4.632 X)$ & April 2011 & 0.724 & 2.73 & 26.25 & 0.0004 \\
\hline$X=\mathrm{B} 1 /(\mathrm{B} 2+\mathrm{B} 3+\mathrm{B} 4)$ & $Y=26.606 \times \mathrm{EXP}(-4.093 X)$ & July 2011 & 0.793 & 1.49 & 33.3669 & 0.0001 \\
\hline$X=\mathrm{B} 4 /(\mathrm{B} 1+\mathrm{B} 2+\mathrm{B} 3)$ & $Y=31.514 \times \operatorname{EXP}(-5.69 X)$ & October 2011 & 0.670 & 1.89 & 30.45 & $5.9 \mathrm{E}-05$ \\
\hline$X=\mathrm{B} 4 /(\mathrm{B} 1+\mathrm{B} 2+\mathrm{B} 3)$ & $Y=23.967 \times \operatorname{EXP}(-10.65 X)$ & January 2010 & 0.538 & 0.28 & 15.14 & 0.0019 \\
\hline$X=\mathrm{B} 1 /(\mathrm{B} 3+\mathrm{B} 4)$ & $Y=36.974 \times \operatorname{EXP}(-5.181 \times X)$ & April 2010 & 0.598 & 0.44 & 14.88 & 0.003 \\
\hline$X=\mathrm{B} 1 /(\mathrm{B} 3+\mathrm{B} 4)$ & $Y=433.24 X^{2}-458.458 X+123.97$ & July 2010 & 0.813 & 1.93 & 21.71 & 0.00023 \\
\hline$X=\mathrm{B} 1 /(\mathrm{B} 2+\mathrm{B} 3+\mathrm{B} 4)$ & $Y=958.32 \times \operatorname{EXP}(-10.59 X)$ & October 2010 & 0.702 & 3.16 & 16.45 & 0.0048 \\
\hline$X=\mathrm{B} 4 /(\mathrm{B} 1+\mathrm{B} 2+\mathrm{B} 3)$ & $Y=4.1263 \times \exp (-3.171 x)$ & January 2009 & 0.462 & 0.38 & 10.32 & 0.0075 \\
\hline$X=\mathrm{B} 4 /(\mathrm{B} 1+\mathrm{B} 2+\mathrm{B} 3)$ & $Y=7.4876 \times \exp (-2.318 x)$ & April 2009 & 0.490 & 1.10 & 12.48 & 0.0038 \\
\hline$X=\mathrm{B} 1 /(\mathrm{B} 3+\mathrm{B} 4)$ & $Y=53.959 \times \exp (-4.854 x)$ & July 2009 & 0.538 & 1.66 & 18.64 & 0.0005 \\
\hline$X=\mathrm{B} 1 /(\mathrm{B} 2+\mathrm{B} 3+\mathrm{B} 4)$ & $Y=19.174 \times \operatorname{EXP}(-3.053 X)$ & October 2009 & 0.693 & 1.08 & 18.02 & 0.0028 \\
\hline
\end{tabular}

Table 3 The quarterly average relative error list in Poyang Lake from 2009 to 2012

\begin{tabular}{llll}
\hline Month & $\begin{array}{l}\text { Modeling } \\
\text { points }\end{array}$ & $\begin{array}{l}\text { Verification } \\
\text { points }\end{array}$ & $\begin{array}{l}\text { The average } \\
\text { relative error (\%) }\end{array}$ \\
\hline January 2009 & 14 & 6 & 48.1 \\
April 2009 & 15 & 5 & 52.5 \\
July 2009 & 18 & 6 & 31.7 \\
October 2009 & 10 & 5 & 31.4 \\
January 2010 & 15 & 9 & 33.3 \\
April 2010 & 12 & 7 & 35.1 \\
July 2010 & 12 & 3 & 45.5 \\
October 2010 & 9 & 3 & 31.9 \\
January 2011 & 7 & 8 & 40.4 \\
April 2011 & 12 & 3 & 34.7 \\
July 2011 & 12 & 12 & 32.7 \\
October 2011 & 17 & 8 & 41.3 \\
January 2012 & 11 & 5 & 16.5 \\
April 2012 & 15 & 9 & 24.1 \\
July 2012 & 53 & 29 & 36.7 \\
October 2012 & 15 & 9 & 36.9 \\
\hline
\end{tabular}

January, the chlorophyll- $a$ concentration was low in general; the highest value was less than $2 \mu \mathrm{g} \mathrm{L}^{-1}$ (deep green and green color in Fig. 6) and the spatial distribution difference was not obvious. The relatively high value in 2011 was caused by the flood in 2010, which was the strongest flood after 1998 in this region. In April, the chlorophyll$a$ concentration value was between 2 and $6 \mu \mathrm{g} \mathrm{L}^{-1}$. It was also low in general for this season apart from several relatively high-value points near the bank of northern and middle Poyang Lake.
The relatively large water surface scope in April 2010 was also due to the strong flood in 2010. The chlorophyll- $a$ concentration distribution was not even in the summer and autumn. The maximal chlorophyll- $a$ concentration value accounted for more than $10 \mu \mathrm{g} \mathrm{L}{ }^{-1}$ in July. There are certain areas with extremely high values in the wide water surface region in the middle and south of Poyang Lake and inflow areas of river inlets. A small area in the south of Poyang Lake also had several high values in autumn.

\section{Spatial and temporal variations' analysis}

Spatial fluctuation characteristics

Figure 7 shows that there were dramatic changes in the chlorophyll- $a$ concentration distribution in different seasons. The fluctuation extent was low in the dry season and higher in the wet season. This means that the chlorophyll- $a$ concentration had a steady low value in January and April, but a relatively high value with enhanced fluctuation in the summer and autumn. Dramatic fluctuations in the autumn show that the chlorophyll- $a$ concentration has increased in the last 4 years and that its increasing scope was highest in autumn.

Temporal fluctuation characteristics

Figure 8 shows that the Poyang Lake chlorophyll- $a$ concentration varied inter-annually from 1 to $15 \mu \mathrm{g} \mathrm{L}^{-1}$. Its average value was $5 \mu \mathrm{g} \mathrm{L}^{-1}$ in 2009 , increased to $6 \mu \mathrm{g} \mathrm{L}^{-1}$ in 2010 , reached $6.5 \mu \mathrm{g} \mathrm{L}^{-1}$ in 2011 , and then 
Fig. 6 Spatial distribution of chlorophyll- $a$ concentration from 2009 to 2012 in Poyang Lake
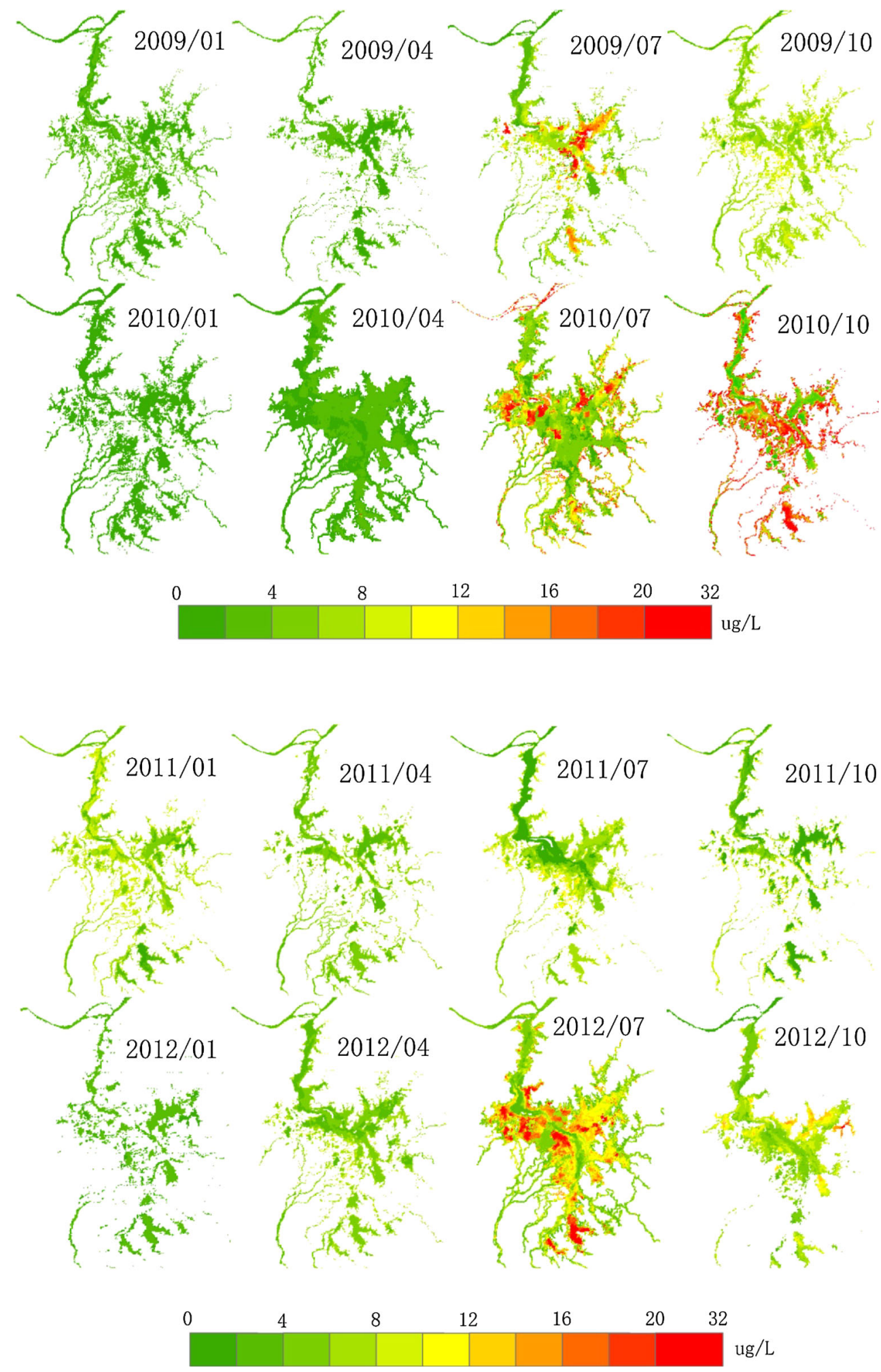

fell to $6.2 \mu \mathrm{g} \mathrm{L}^{-1}$ in 2012. This shows a slowly increasing trend for chlorophyll- $a$ concentration variation.

Annual variations of chlorophyll- $a$ concentration clearly show seasonal fluctuation characteristics. Taking year 2012 as an example, an obvious "low-high-low" model existed in this year. In general, the chlorophyll- $a$ concentration value in January and April was much lower; it increased to approximately $10 \mu \mathrm{g} \mathrm{L}^{-1}$ in July, decreased in October and again decreased to the lowest value in January of the following year. 
Fig. 7 Fluctuations of chlorophyll- $a$ concentration for each season from 2009 to 2012 in Poyang Lake
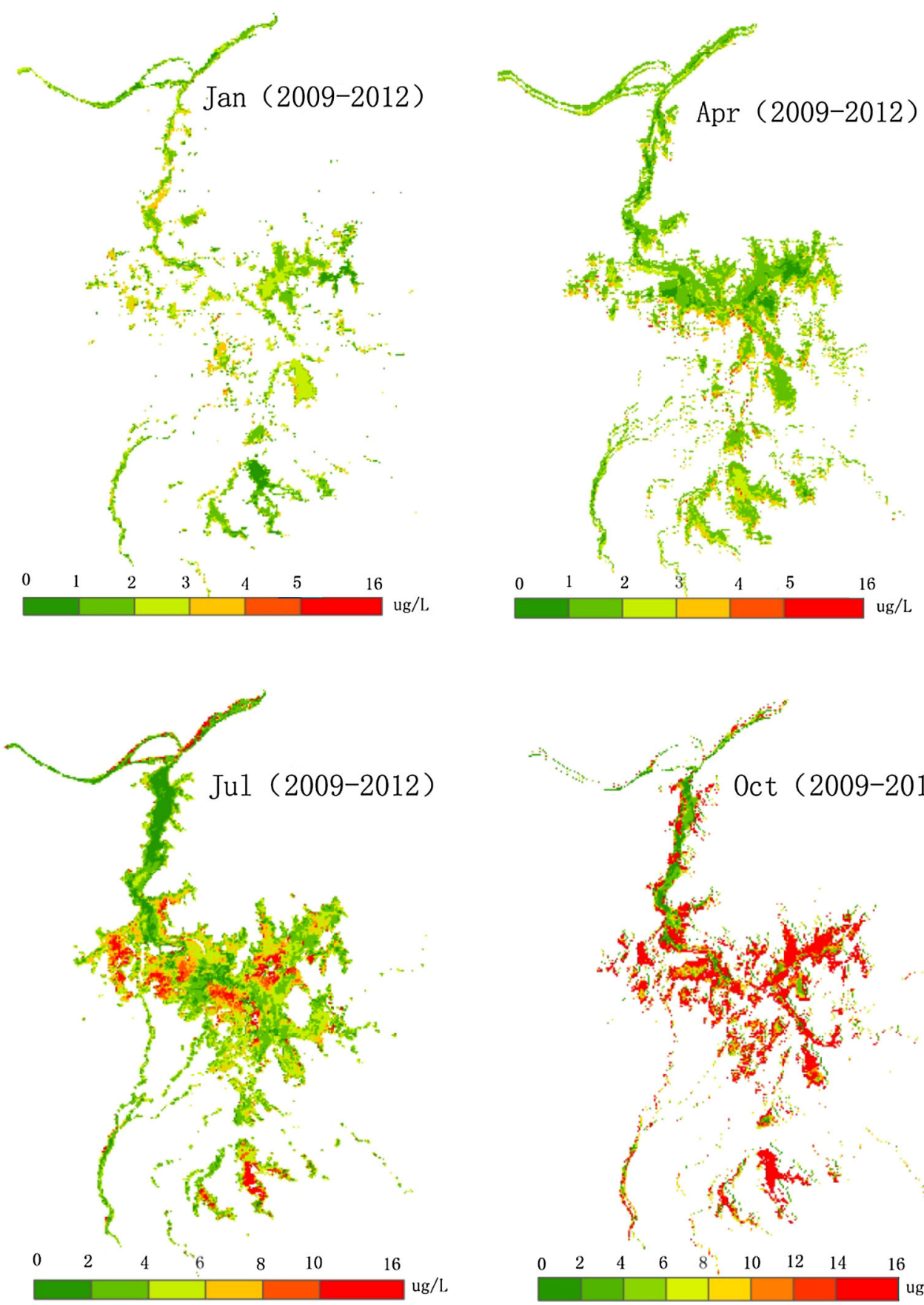

This seasonal fluctuation feature had a close relationship with the hydrological features of Poyang Lake. In the winter (represented by January), the Poyang Lake water surface was relatively small because the water level was very low. The average water temperature in this season from 2009 to 2012 was $5-7{ }^{\circ} \mathrm{C}$. The low water temperature and the high water-flow speed caused the phytoplankton to increase slowly. As the weather became warmer in the spring (represented by April), the average water temperature was approximately $16-18{ }^{\circ} \mathrm{C}$, and the water level increased with the precipitation increase. This led to a decrease in the water-flow speed and a gradual algae growth speed increase in the spring, resulting in an increased chlorophyll- $a$ concentration. In the summer (represented by July), the average water temperature was approximately $29-31{ }^{\circ} \mathrm{C}$, and the water surface area was relative large. The chlorophyll- $a$ concentration value increased to the highest value in this season. In the autumn (represented by October), the average water temperature was approximately $21-22^{\circ} \mathrm{C}$. Although the chlorophyll$a$ concentration had a relatively high value throughout the year, it was still lower than in the summer. 
To discover the relationship between water temperature and chlorophyll- $a$ concentration in Poyang Lake, 197 original records measuring temperature data were collected. By the Kolmogorov-Smirnov testing method and Pearson correlation analysis, the results show that, at a level of 0.01 , chlorophyll- $a$ concentration and water temperature had a significant correlation and the Pearson correlation index was 0.536 (see in Table 4). This means that the two parameters are moderately correlated (Salavati et al. 2009). Figure 9 shows the relationship between water temperature and chlorophyll- $a$ concentration. The regression equation is $y=0.113 x+1.414\left(R^{2}=0.287\right)$.

\section{Driving-force discussion}

The Poyang Lake chlorophyll- $a$ concentration spatial distribution characteristics had a close relationship with contaminants brought from the five rivers and the surrounding pollution area. Previous studies showed that the slowly increasing chlorophyll- $a$ concentration was affected by lake-nutrient conditions, water temperature, water level, water-flow speed, storms and other factors (Jin et al. 2011; $\mathrm{Hu}$ et al. 2010) caused by human activities. The high chlorophyll- $a$ concentration in the northern area of Poyang Lake may be explained by the intensive sand-dredging activities started in approximately 2001 (Zhong and Chen 2005), which caused sediments to be resuspended and increased sediment and nutrient concentrations. It was

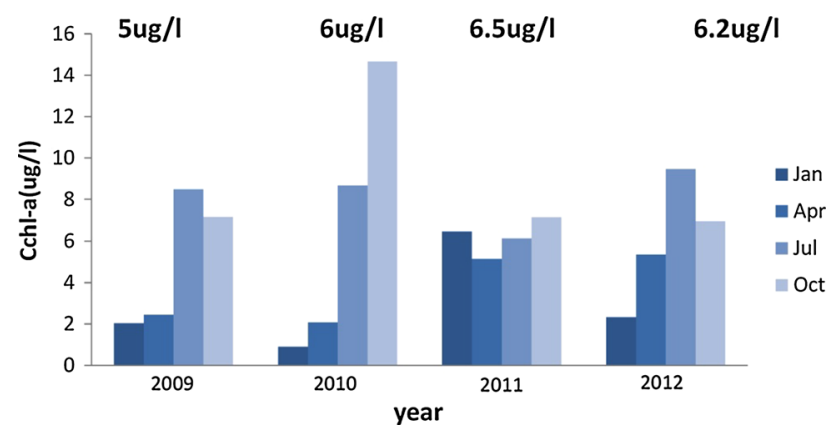

Fig. 8 Variation of average chlorophyll- $a$ concentration from 2009 to 2012 in Poyang Lake

Table 4 Correlations between chlorophyll- $a$ concentration and water temperature in Poyang Lake
** Correlation is significant at the 0.01 level (2-tailed)

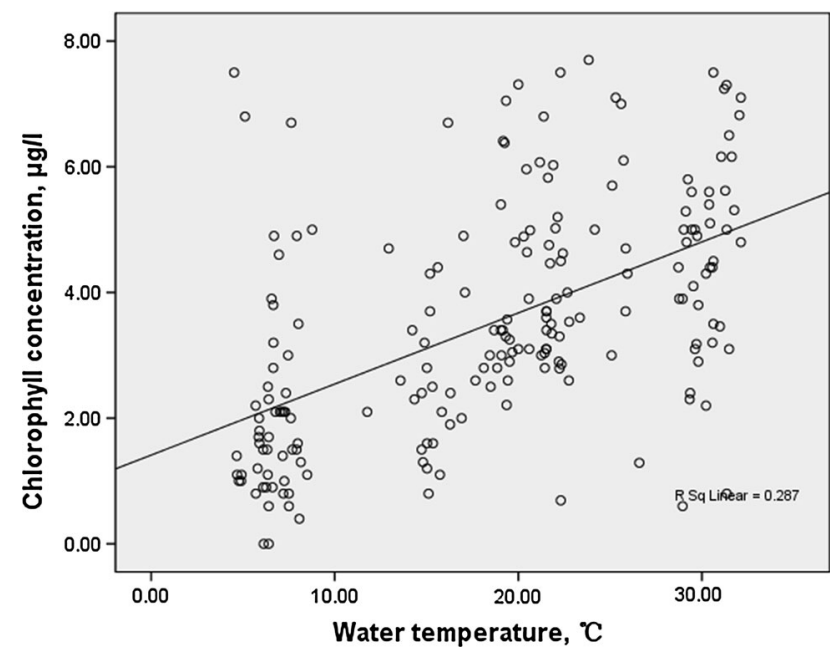

Fig. 9 The linear model of water temperature and chlorophyll concentration in Poyang Lake

reported that there are approximately 200 high-power, large sand-dredging machines capable of dredging all of the sand within $30 \mathrm{~m}$ of the water's surface within a $100 \mathrm{~m}$ radius. Moreover, out-of-order sand dredging and uncontrolled sand excavation led to pollution discharged by vessels and ships and the release of large quantities of nutrients from the riverbed. There were increasing trends in total N (TN) and total P (TP) concentrations from 2009 to 2012, which may also be proof of an increase in the chlorophyll- $a$ concentration (Wu et al. 2013a; Li and Zhang 2011a). The middle and western area of Poyang Lake had a high value, which was perhaps caused by contamination such as the nutrients $\mathrm{N}$ and $\mathrm{P}$ being brought in by the rivers (Hu et al. 2010). Pollution discharge from vessels could also have influenced the water quality of Poyang Lake, causing a high-value area along the shipping route in the central lake in summer. In the middle and eastern area of Poyang Lake, industry and agriculture development near the bank area increased the population and generated a large amount of polluted water entering Poyang Lake, which caused a high-concentration value (He et al. 2013). The upstream area of the Xinjiang and Raohe rivers had high pollution levels from copper mines, phosphorite mines, etc. (Wan and Jiang 2006; Li and Zhang

\begin{tabular}{lll}
\hline & Chlorophyll- $a$ concentration & Water temperature \\
\hline $\begin{array}{ll}\text { Chlorophyll- } a \text { concentration } \\
\text { Pearson correlation }\end{array}$ & 1 & $0.536^{* *}$ \\
Sig. (2-tailed) & 197 & 0.000 \\
$N$ & & 197 \\
Water temperature & $0.536^{* *}$ & \\
Pearson correlation & 0.000 & 1 \\
Sig. (2-tailed) & 197 & 197 \\
$N$ & & \\
\hline
\end{tabular}


2011b), which could cause the high-concentration value that occurred in the river mouth area of Poyang Lake. The Junshan lake and other small lakes located to the south of Poyang Lake had relatively high-concentration values because aquiculture such as crab feeding was popular at there.

\section{Conclusions}

The present study examined the spatial and temporal distribution and variations of chlorophyll- $a$ concentration from 2009 to 2012 in Poyang Lake, China. The average chlorophyll- $a$ concentration value increased from $5 \mu \mathrm{g} \mathrm{L}^{-1}$ in 2009 to $6.2 \mu \mathrm{g} \mathrm{L}^{-1}$ in 2012. High-value areas were located near the bank of north Poyang Lake, central and south of the main channel, and near five inflowing river entrances. It was low in the winter and spring and had relatively high values in the summer and autumn. This seasonal fluctuation had a close relationship with hydrological features of Poyang Lake such as water temperature. Intensive human activities are the main driving forces for the chlorophyll- $a$ concentration increasing.

However, the semi-analytical method used for chlorophyll- $a$ concentration reversion in this study only used the simple-band combination of MODIS; multi-band analytical models need to be carried out in the future to advance the reversion efficiency and accuracy.

Acknowledgments Special thanks are due to the Lake Poyang Laboratory for Wetland Ecosystem Research (PLWER) for providing the foundation for the experiment. We are grateful to Prof. Yuwei Chen and Dr. Lu Zhang for their help with field work preparation and for providing a portion of the data for this study. This study was financially supported by the Chinese Industry Public Welfare Scientific Research Program on environmental protection field (grant 201109075), Science \& Technology Basic Research Program of China (2011FY110400), and the Chinese Academy of Sciences Informatization Scientific Research Program (grant XXH12504-1-01). We also thank the anonymous reviewers for their detailed comments and suggestions.

\section{References}

Binding C, Jerome J, Bukata R, Booty W (2010) Suspended particulate matter in Lake Erie derived from MODIS aquatic colour imagery. Int J Remote Sens 31(19):5239-5255

Binding C, Greenberg T, Bukata R (2012) An analysis of MODISderived algal and mineral turbidity in Lake Erie. J Great Lakes Res 38(1):107-116

Carder K, Chen F, Cannizzaro J, Campbell J, Mitchell B (2004) Performance of the MODIS semi-analytical ocean color algorithm for chlorophyll. Adv Space Res 33(7):1152-1159

Chen J, Wen Z, Xiao Z (2011) Spectral geometric triangle properties of chlorophyll- $a$ inversion in Taihu Lake based on TM data. J Water Resour Prot 3(1):67-75
Chen J, Quan W, Wen Z, Cui T (2013a) An improved three-band semi-analytical algorithm for estimating chlorophyll- $a$ concentration in highly turbid coastal waters: a case study of the Yellow River estuary, China. Environ Earth Sci 69(8):2709-2719

Chen J, Zhang M, Cui T, Wen Z (2013b) A review of some important technical problems in respect of satellite remote sensing of chlorophyll- $a$ concentration in coastal waters. IEEE J Sel Topics Appl Earth Obs Remote Sens 6(5):2275-2289

Chen J, Zhang X, Quan W (2013c) Retrieval chlorophyll- $a$ concentration from coastal waters: three-band semi-analytical algorithms comparison and development. Opt Express 21(7): 9024-9042

Dekker A, Vos R, Peters S (2001) Comparison of remote sensing data, model results and in situ data for total suspended matter (TSM) in the southern Frisian lakes. Sci Total Environ 268(1):197-214

Dekker AG, Vos R, Peters S (2002) Analytical algorithms for lake water TSM estimation for retrospective analyses of TM and SPOT sensor data. Int J Remote Sens 23(1):15-35

Deng X, Zhao Y, Wu F, Lin Y, Lu Q, Dai J (2011) Analysis of the trade-off between economic growth and the reduction of nitrogen and phosphorus emissions in the Poyang Lake Watershed, China. Ecol Model 222(2):330-336

Domenikiotis C, Loukas A, Dalezios N (2003) The use of NOAA/ AVHRR satellite data for monitoring and assessment of forest fires and floods. Nat Hazards Earth Syst Sci 3(1/2):115-128

Gitelson AA, Dall'Olmo G, Moses W, Rundquist DC, Barrow T, Fisher TR, Gurlin D, Holz J (2008) A simple semi-analytical model for remote estimation of chlorophyll in turbid waters: Validation. Remote Sens Environ 112(9):3582-3593

Härmä P, Vepsäläinen J, Hannonen T, Pyhälahti T, Kämäri J, Kallio K, Eloheimo K, Koponen S (2001) Detection of water quality using simulated satellite data and semi-empirical algorithms in Finland. Sci Total Environ 268(1):107-121

He C, Liu J, Li J, Liang X, Chen X-P, Lei Y-R, Zhu D (2013) Spatial distribution, source analysis, and ecological risk assessment of DDTs in typical wetland surface soils of Poyang Lake. Environ Earth Sci 68(4):1135-1141

$\mathrm{Hu}$ C (2009) A novel ocean color index to detect floating algae in the global oceans. Remote Sens Environ 113(10):2118-2129

Hu C, Zhou W, Wang M, Wei Z (2010) Inorganic nitrogen and phosphate and potential eutrophication assessment in Lake Poyang. J Lake Sci 22(5):723-728

Huang W, Wu Y, Shu J (1998) Hydrographical environmental problems and countermeasures of main Lakes and reservoirs in China. J Lake Sci 10(3):83-90

Huang G, Liu C, Yue X (2010) The inversion of chlorophyll $a$ concentration in Poyang Lake. Shanxi Archit 36(34):357-359

Jain SK, Singh R, Jain M, Lohani A (2005) Delineation of floodprone areas using remote sensing techniques. Water Resour Manag 19(4):333-347

Jiang H (2012) An research on the quantitative model of chlorophyll $a$ concentration in Poyang Lake. Sci Surv Mapp 37(6):49-52

Jin X, Ye C, Yan C, Ren B, Zhang Y, Wang X, Wang Y (1999) Comprehensive treatment plan for key-polluted regions of Lake Taihu. Res Environ Sci/Huanjing Kexue Yanjiu 12(5):1-5

Jin G, Xie D, Deng H, Yan Y, Lin M, Wang Y (2011) On seasonal hydrographic variety and environmental capacity of Poyang Lake. Acta Agric Univ Jiangxiensis 33(2):388-393

Li R, Li J (2004) Satellite remote sensing technology for lake water clarity monitoring: an overview. Environ Inform Arch 2:893-901

Li R, Zhang Y (2011a) Analysis of spatial and temporal variation of water quality and its influencing factors in Poyang Lake. Water Resour Prot 27(6):9-13 
Li R, Zhang Y (2011b) Temporal water quality change of poyang lake and the analysis of influencing factors. Water Resour Prot 27(6):8-18

Liu X, Shen F, Zhu W (2009) The quantitative inversion of the concentration of suspended sediment at the estuary of Yangtze River based on MWEIS data. Resour Environ Yangtze Basin 18(11):1026-1030

Liu K, Zhao W, Guo X (2012) An research on the estimating of nitrogen content in wetland plants based on measured spectra on the ground. Spectrosc Spectr Anal 32(2):465-471

Lunetta RS, Knight JF, Ediriwickrema J, Lyon JG, Worthy LD (2006) Land-cover change detection using multi-temporal MODIS NDVI data. Remote Sens Environ 105(2):142-154

Matthews MW (2011) A current review of empirical procedures of remote sensing in inland and near-coastal transitional waters. Int J Remote Sens 32(21):6855-6899

Miller RL, McKee BA (2004) Using MODIS Terra $250 \mathrm{~m}$ imagery to map concentrations of total suspended matter in coastal waters. Remote Sens Environ 93(1):259-266

Salavati M, Hadian MR, Mazaheri M, Negahban H, Ebrahimi I, Talebian S, Jafari AH, Sanjari MA, Sohani SM, Parnianpour M (2009) Test-retest reliabty of center of pressure measures of postural stability during quiet standing in a group with musculoskeletal disorders consisting of low back pain, anterior cruciate ligament injury and functional ankle instability. Gait Posture 29(3):460-464

Shankman D, Liang Q (2003) Landscape changes and increasing flood frequency in China's Poyang Lake Region*. Prof Geogr 55(4):434-445

Shankman D, Keim BD, Song J (2006) Flood frequency in China's Poyang Lake region: Trends and teleconnections. Int J Climatol 26(9):1255-1266

Sipelgas L, Ossipova V, Raudsepp U, Lindfors A (2009) A bio-optical model for the calculation of suspended matter concentration from MODIS data in the Pakri Bay, the Gulf of Finland. Boreal Environ Res 14(3):415-426

Smith VH, Schindler DW (2009) Eutrophication science: where do we go from here? Trends Ecol Evol 24(4):201-207

Tang J (2004) Water spectral measurement and analysis I: measurement above water. J Remote Sens 8(1):37-44

Unesco S (1966) Determination of photosynthetic pigments in sea water. Monographs Oceanogr method-UNESCO, I

Wan J, Jiang S (2006) The water environment analysis and comprehensive treatment of Poyang Lake. Water Resour Prot 22(3):24-27
Wang M (2008) 2, ZHOU Wenbin1, 2 \& HU Chunhua1, 2 (1: Key Laboratory of Lake Poyang Ecology and Bio-resource Utilization, Ministry of Education, Nanchang University, Nanchang 330047, PR China) (2: Institute of Environmental Science and Engineering, Nanchang University, Nanchang 330031, PR China); Status of nitrogen and phosphorus in waters of Lake Poyang Basin [J]. J Lake Sci 3

Wang T, Huang W, Liu Y (2007) An Eutrophication monitoring model of Poyang Lake based on hyperspectral remote sensing. Sci Surv Mapp 23(4):44-46

Wu Y, Ji W (2002) Study on Jiangxi Poyang Lake national nature reserve. Forest Publishing House, Beijing

Wu M, Wang X (2005) The water quality monitoring of Chaohu Lake based on MODIS data. J Lake Sci 17(2):110-113

Wu G, Cui L, He J, Duan H, Fei T, Liu Y (2013a) Comparison of MODIS-based models for retrieving suspended particulate matter concentrations in Poyang Lake, China. Int J Appl Earth Obs Geoinf 24:63-72

Wu Z, Cai Y, Liu X, Xu CP, Chen Y, Zhang L (2013b) Temporal and spatial variability of phytoplankton in Lake Poyang: The largest freshwater lake in China. J Great Lakes Res 39(3):476-483

$\mathrm{Xu} \mathrm{H}$ (2006) Modification of normalised difference water index (NDWI) to enhance open water features in remotely sensed imagery. Int J Remote Sens 27(14):3025-3033

$\mathrm{Xu} \mathrm{D}$, Xiong M, Zhang J (2001) Analysis on hydrologic characteristics of Poyang Lake. Yangtze River 32(2):21-27

Yan W, Zhang S, Sun P, Seitzinger SP (2003) How do nitrogen inputs to the Changjiang basin impact the Changjiang River nitrate: a temporal analysis for 1968-1997. Global Biogeochem Cycles 17(4):1091-1099

Yu Z, Chen X, Zhou B, Tian L, Yuan X, Feng L (2012) Assessment of total suspended sediment concentrations in Poyang Lake using HJ-1A/1B CCD imagery. Chin J Oceanol Limnol 30:295-304

Zhang B (1988) Research on Poyang Lake. Shanghai scientific \& Technical Publishers, China

Zhang Y, Wang J, Rang Y, Yang F, Cao X, Guo H (2013) The estimating of concentration of chlorophyll a in Poyang Lake based on measured spectra and MODIS data. Resour Environ Yangtze Basin 22(8):1081-1089

Zhao L, Wei H, Feng S (2002) Annual cycle and budgets of nutrients in the Bohai Sea. J Ocean Univ Qingdao 1(1):29-37

Zhong Y, Chen S (2005) Impact of dredging on fish in Poyang Lake. Jiangxi Fish Sci Technol 1:15-18

Zhou C, Luo J, Yang X (2003) Geoscientific In-terpretation and analysis of remore sensing images. Science Press, Beijing 